\title{
Perinatal asphyxia syndrome in the foal: review and a case report
}

\author{
Noreen Galvin $^{1}$ and Donald Collins ${ }^{2}$ \\ 1 Troytown Equine Hospital, Green Road, Kildare Town, Co Kildare, Ireland \\ 2 Kildangan Stud, Monasterevin, Co. Kildare, Ireland
}

This report presented a brief overview of the literature on the perinatal asphyxia syndrome (PAS) in foals as a prelude to a description of the investigation and treatment of acute onset seizures in a 24-hour-old Thoroughbred colt foal.

PAS can cause a wide variety of clinical abnormalities, of which seizures due to encephalopathy are the most significant. The structural and biochemical components of CNS neurones are disrupted by the shift from oxidative to anaerobic metabolism, with a resultant deficit in cellular energy. The cells succumb to the combined effects of acidosis, neurotoxic activities of glutamate, nitric oxide and free radicals, lipid peroxidation, accumulation of intracellular calcium and destructive overactivity of intracellular enzymes. Concurrently, the hypoxia affects other organ systems and management of foals presenting with CNS signs requires the veterinarian to undertake a thorough clinical examination and to institute appropriate therapy for the various derangements induced by the hypoxic-ischaemic episode. Diazepam $(0.1$ to $0.2 \mathrm{mg} / \mathrm{kg}$ bwt) can be used for short-term control of seizures; phenobarbital (2 to $10 \mathrm{mg} / \mathrm{kg} \mathrm{bwt}$ ) may be required for more prolonged treatment of recurrent seizures. The needs of the affected foal for nutrients, fluids and electrolytes, antimicrobial therapy and ancillary therapies were discussed in the literature review and illustrated in the case report.

\author{
Key words \\ Horse, \\ Foal, \\ Perinatal asphyxia \\ syndrome, \\ Encephalopathy.
}

Irish Veterinary Journal

Volume 57: 707 - 7|4, 2004

\section{Introduction}

Asphyxia is due to impaired delivery of oxygen to organs and cells. The syndrome of perinatal asphyxia in foals is usually a consequence of a combination of ischaemia and hypoxaemia. The syndrome may cause a wide variety of clinical abnormalities depending on the degree, the duration, and the target organ of the insult. Two categories of PAS have been described. Category 1 consists of foals that have a normal delivery, with

Address for correspondence:

\section{Noreen Galvin}

Bohergoy

Maddenstown

The Curragh

Co Kildare

Ireland.

Tel: 00447788537951 (Scotland)

E-mail: galvinnoreen@eircom.net
Products used in the treatment of perinatal asphyxia in the foal.

$\begin{array}{lll}\begin{array}{ll}\text { Product } \\ \text { Diazepam }\end{array} & \begin{array}{l}\text { Trade name } \\ \text { Valium }\end{array} & \begin{array}{l}\text { Manufacturer } \\ \text { Roche }\end{array} \\ \text { Gentamicin } & \text { Gentaject } & \text { Franklin Pharmaceuticals } \\ \text { Ceftiofur } & \text { Excenel } & \text { Pharmacia and upjohn } \\ \text { Ketoprofen } & \text { Ketofen 10\% } & \text { Merial animal health } \\ \text { Allopurinol } & \text { Allopurinol } & \text { Non-proprietary } \\ \text { Vitamin E } & \text { Vitenium } & \text { Novartis animal health } \\ \text { Polyionic fluids } & \text { Isolec } & \text { Ivex UK } \\ \text { Parenteral nutrition } & \text { Clinomel } & \text { Baxters } \\ \text { Phenobarbital } & \text { Phenobarbital } & \text { Non-propriety } \\ \text { Omeprazole } & \text { losec } & \text { Astra UK } \\ \text { Magnesium sulphate } & \text { Mag sul 25\% } & \text { Arnolds } \\ \text { DMSO } & & \text { VWR International UK } \\ \text { Triple lumen catheter } & & \text { Mila International USA } \\ \text { Indwelling stomach tube } & & \text { Mila International USA }\end{array}$




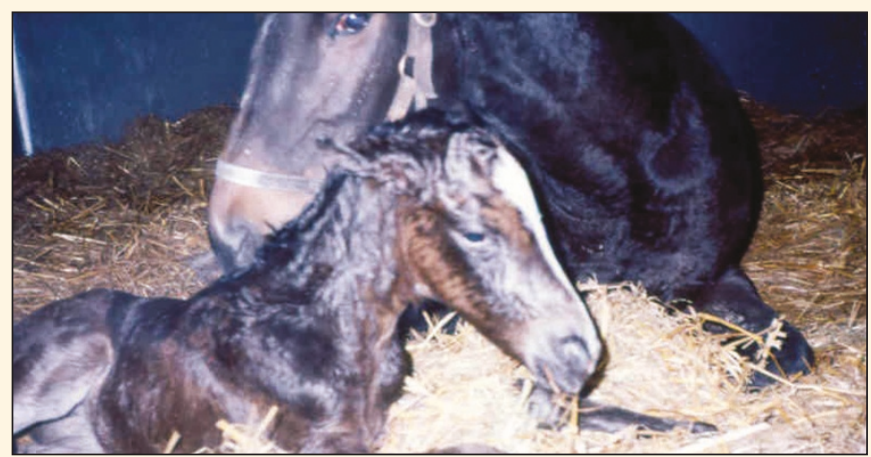

When lying, diarrhoeic foals need to be maintained in sternal recumbency and turned frequently to avoid pressure sores.

normal post-natal behaviour; the onset of clinical signs is likely to be within 24 hours of birth. Category 2 foals have an abnormal birth and are weak and possibly recumbent from birth; these foals have a much poorer prognosis (Hess-Dudar and Rossdale, 1996a). Foals that are suffering from the CNS disturbances of PAS have been referred to as "dummies", "barkers", or "wanderers". The term 'neonatal maladjustment syndrome' is commonly used to describe the condition; however, perinatal asphyxia syndrome (PAS) is a more accurate term.

\section{Predisposing factors}

The principal causes of hypoxia in the foetus and neonate are listed in Table 1. Maternal factors that contribute to perinatal asphyxia are those that cause hypotension or reduced tissue oxygenation. Placental pathology will impair uteroplacental perfusion. Areas of chronic placental separations may lead to chronic hypoxia of the foetus. The most acute cause of perinatal asphyxia is complete premature placental separation at birth (red bag delivery). Twinning will lead to reduced area of placentation available for perfusion to each foetus and, also, will predispose to dystocia and its associated complications: compression of the umbilical cord, placental separation, and aspiration of meconium. Factors that lead to decreased tissue oxygenation and blood flow in the neonate include sepsis, prematurity and dysmaturity (Furr, 1996).

\section{Pathogenesis}

Hypoxic-ischaemic insults affect many organs. The CNS may suffer the most profound damage: inadequate supplies of oxygen and glucose trigger a cascade of interrelated changes as the neurones react to the deficient supply of energy (Volpe, 1995). There is massive release of glutamate (leading to a large influx of calcium ions), increased production of free radicals, diminished ability of the sodium pumps, altered distribution of ions (large quantities of sodium, chloride and calcium enter the neurones, while potassium leaks out). The new ionic gradients draw water into the neurones and within the swollen cell the excess calcium overactivates many enzyme systems that damage vital cell constituents and kill the neurones, also damaged by oxygen-free radicals that initiate the peroxidation of phospholipids in their cell membranes (Westbrook, 1993; Volpe, 1995).

\section{TABLE 1: Factors that may lead to the perinatal asphyxia syndrome in foals}

\begin{tabular}{|c|c|}
\hline \multirow[t]{4}{*}{ Maternal } & Respiratory disease \\
\hline & Endotoxaemia \\
\hline & Haemorrhage/anaemia \\
\hline & Surgery/caesarean delivery \\
\hline \multirow[t]{4}{*}{ Placental } & Placentitis (bacterial, fungal, endophyte) \\
\hline & Chronic uteroplacental separation \\
\hline & Acute/premature uteroplacental separation (red bag \\
\hline & delivery) \\
\hline \multirow[t]{7}{*}{ Foetal } & Twinning \\
\hline & Congenital abnormalities \\
\hline & Dystocia \\
\hline & Aspiration of meconium \\
\hline & Sepsis \\
\hline & Prematurity \\
\hline & Dysmaturity \\
\hline
\end{tabular}

\section{Clinical findings}

Clinical signs vary depending on the degree and the duration of the asphyxia and on the system most affected by the insult. CNS signs can be very variable depending on the degree of hypoxia. Mild hypoxia may manifest with signs as subtle as the foal being 'hyperexcitable' (Vaala, 2002). Other symptoms may include generalised weakness, lack of interest in the mare, lack of suck reflex, apparent blindness, walking into the mare, walking into walls, recumbency and seizures (Hess-Dudan and Rossdale, 1996a,b). Where there is severe CNS depression and coma there will be loss of central regulation of respiration, temperature and blood pressure, leading ultimately to death (Vaala, 2002).

Gastrointestinal manifestations of PAS may include ileus, colic, retained meconium, necrotising enterocolitis, and gastric ulceration. Adverse effects on the cardiovascular system include reduced myocardial contractility, decreased cardiac output, and systemic hypotension; these effects, in turn, can increase the hypoxic insult to other systems. Asphyxia can damage the respiratory centre in the brain. The lungs are vulnerable to secondary atelectasis because the decrease in pulmonary perfusion impairs the delivery of the substrates that the pneumocytes require for the production of surfactant. Damage to renal tubular cells may be seen clinically as decreased urine output. Hepatic and endocrine systems may be involved; however, there is not much literature on these effects in neonatal foals (Furr, 1996).

While abnormalities of one organ system may predominate it is important to evaluate all other systems, and determine the degree of involvement. 


\section{Differential diagnosis}

Differential diagnosis of seizures in neonatal foals (Vaala, 2002) includes:

(i) metabolic disorders (hypocalcaemia, hypomagnesaemia, hypo/hyperglycaemia, hypo/hypernatraemia, azotaemia and hepatoencephalopathy),

(ii) infectious conditions (meningitis, septicaemia and equine herpesvirus infection),

(iii) trauma to cranium or spinal column,

(iv) congenital abnormalities (hydrocephalus, occipitalatlantoaxial malformations),

(v) toxins.

Once these differentials can be ruled out, perinatal asphyxia must be considered as a cause of the neurological deficits.

\section{Clinical pathology}

There are no pathognomonic clinicopathological changes for PAS. Most often, haematology is normal but when concurrent sepsis is present there may be leucopaenia or leukocytosis; importantly, even in sepsis the haemogram may remain unchanged. In moderate to severe asphyxia there may be acidosis with a $\mathrm{pH}$ less than 7.3 and bicarbonate concentration less than $20 \mathrm{mmol} / \mathrm{L}$. Respiratory depression will lead to hypoxaemia $\left(\mathrm{PaO}_{2}<60 \mathrm{mmHg}\right)$ and hypercapnoea $\left(\mathrm{PaCO}_{2}\right.$ $>65 \mathrm{mmHg}$ ).

Substantial elevations in creatine kinase may correlate with a hypoxic-ischaemic insult to the neonate in utero or during the birth; however, it may also be an indicator of muscle trauma either at birth or after (Madigan, 1997). Increases in plasma creatinine concentrations in the first 24 hours of life can occur in neonates in the absence of renal disease; most likely it is an indicator of adverse maternal and/or placental conditions and will reduce over the following days. However, if it remains elevated then renal dysfunction must be considered.

\section{Treatment}

\section{Supportive therapy}

The immediate environment of a convulsing or hyperexcitable foal should be as quiet and dark as possible to minimise the effects of outside stimuli. Recumbent foals need to be kept warm and dry, maintained in sternal recumbency and turned frequently to avoid pressure sores.

\section{Anticonvulsive therapy}

Seizures result in increased demand for oxygen in brain and muscle tissues, further adding to the hypoxic insult. The aim of seizure control is to prevent further damage to the CNS and to reduce the risk of trauma to the neonate.

Diazepam (0.1 to $0.2 \mathrm{mg} / \mathrm{kg}$ bwt $)$ when administered i.v. has a rapid action but its effects are of short duration. Phenobarbital is necessary to control severe seizures; the dose (2 to $10 \mathrm{mg} / \mathrm{kg}$ bwt q12h) must be given slowly i.v. to avoid respiratory depression. Abrupt cessation of phenobarbital therapy may

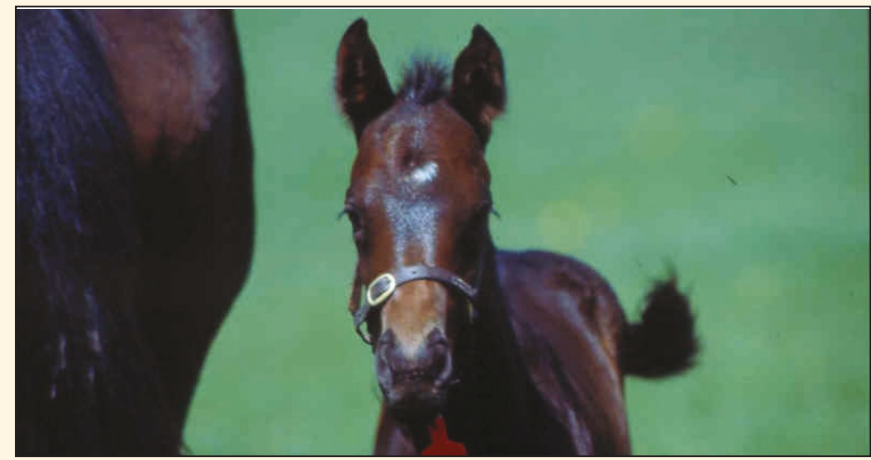

Foals with category I form of perinatal asphyxia syndrome have normal delivery and normal postnatal behaviour but develop symptoms within 24 hours of birth.

result in resumption of seizures; therefore, it may be prudent to gradually decrease the dosages over 24 to 48 hours (Furr, 1996).

\section{Nutritional support}

A neonatal foal should receive $10 \%$ of its body weight in milk each day; if the foal is not sucking, this should be divided into hourly feeds administered via indwelling stomach tube. If there are clinical signs of gastrointestinal dysfunction (colic, ileus, diarrhoea), total enteral feeding is unlikely to be tolerated. The parenteral route can be used as the sole source of nutrition or it may be used to top-up a decreased enteral intake. Complications associated with parentral nutrition include problems with the intravenous catheter, hypokalaemia, hyperlipaemia and hyperglycaemia. Withdrawn of parenteral nutrition must be done gradually over 24 hours.

\section{Fluid and electrolyte therapy}

Overzealous fluid administration is contraindicated in animals suffering from ischaemic encephalopathy, as it may increase cerebral oedema. However, maintenance requirements must be met. Monitoring packed cell volume and total protein concentration are not very accurate in determining the fluid status in the neonate: they have very broad ranges and they may not increase until the foal is severely dehydrated. The volume of parentral nutrition must be taken into account when calculating total maintenance volume. Maintenance requirements would be 5 to $6 \mathrm{ml} / \mathrm{kg}$ bwt $/ \mathrm{h}$ of a balanced polyionic fluid (Hartmann's). There is evidence to suggest that isotonic sodium replacement fluids are not suitable for maintenance in critically ill foals. Buchanan et al. (2003) reported that healthy foals lost weight and their serum sodium concentrations and osmolality increased when they were given a $24 \mathrm{~h}$ infusion of an isotonic sodiumcontaining fluid. Hypokalaemia secondary to hyperglycaemia may be seen during the use of parenteral nutrition; when that happens, potassium supplementation is necessary. Intravenous plasma may be required if passive transfer of immunoglobulins has been inadequate.

Non-invasive blood pressure monitoring, together with data on 
clinical hydration and urine output, may be the most accurate way of determining fluid status in neonates (Corley, $2002 \mathrm{a}, \mathrm{b}$ ). Normal urine production in a suckling foal is $6 \mathrm{ml} / \mathrm{kg}$ bwt $/ \mathrm{h}$ (Brewer et al., 1990). However, in the critically ill foal receiving i.v. infusions, it is the fluid balance (the difference between the volume of all fluids taken in and the volume of urine) that is important; this should be small and represent insensible, faecal and homeostatic fluid loss. Early intervention to restore circulating volume and tissue perfusion is necessary if urine output falls below $66 \%$ of all fluids delivered.

The specific gravity of the urine can be measured, the normal being 1.001 to 1.009 . Dehydration or hypovolaemia will usually result in much higher specific gravity readings (Corley, 2002a).

\section{Antimicrobial therapy}

Antimicrobials have an important role in treatment and prophylaxis of infection in PAS foals. Recumbent foals are at high risk of infection; negative blood culture and normal haemograms may not be enough to rule out ongoing sepsis. Concurrent sepsis or development of secondary sepsis are poor prognostic indicators.

\section{Respiratory support}

Most PAS foals will benefit from intranasal administration of humidified oxygen. Blood gases provide a useful indication of the oxygen status of the foal while recumbent. Maintaining foals in sternal recumbency has been shown to increase $\mathrm{PaO}_{2}$ (Furr, 1996).

Periods of apnoea, either secondary to phenobarbital administration or following hypoxic damage to the respiratory centre, can be treated with caffeine, which is the safest of the methylxanthines. However, overdosing can cause increased CNS, myocardial and gastrointestinal stimulation. In cases of severe respiratory depression, mechanical ventilation may be required.

\section{Specific treatments}

The following drugs have been used in the treatment of perinatal asphyxia in foals.

Dimethylsulphoxide (DMSO)

DMSO ( $\mathrm{gg} / \mathrm{kg}$ bwt i.v. q24 hrs) is a scavenger of free radicals and may reduce further inflammation in the cerebrum. It is administered in a solution at no greater than $20 \%$ concentration, as higher concentrations can cause haemolysis. Alternatively, it can be administered via nasogastric tube.

Vitamin $\mathrm{E}$

Vitamin E, a major antioxidant in the lipid environment, reduces the amount of lipid peroxidation in affected organs. As it is lipid soluble, it may take two to three days to reach therapeutic levels. Therefore, ideally, it needs to be given preinsult, to maximise its effect (Tan and Parks, 1999).

\section{Vitamin C}

Vitamin C (ascorbic acid), a major antioxidant in the aqueous environment, is one of the principal antioxidants in the foetus (Tan and Parks, 1999); it is thought to have a neuroprotective effect.

Thiamine

Administered at 10 to $20 \mathrm{mg} / \mathrm{kg}$ bwt i.v. $\mathrm{ql} 2 \mathrm{~h}$, it may have a role in preventing the glutamate-induced cell death (Vaala, 2002).

\section{Magnesium sulphate}

Magnesium is an NMDA (N-methyl-D-aspartate) receptor antagonist. NMDA mediates the influx of calcium into the cell and in perinatal asphyxia an excess accumulation of intracellular calcium is responsible for the death of neurones. Human studies have shown that magnesium is effective only when given preinsult (Tan and Parks, 1999). However, in one study (Wilkins, 2001) magnesium sulphate infusions were thought to reduce seizures in neonatal foals. Infusion rates were $50 \mathrm{mg} / \mathrm{kg}$ bwt $/ \mathrm{h}$ for the first hour as a loading dose, then reduced to $25 \mathrm{mg} / \mathrm{kg}$ bwt $/ \mathrm{h}$ as a constant-rate infusion.

\section{Allopurinol}

The main property of this drug is as a xanthine oxidase inhibitor. In hypoxia-reoxygenation or ischaemic-reperfusion injuries xanthine oxidase reacts with purine breakdown products to produce oxidants. Allopurinol has been shown to be effective post-insult in hypoxic-ischaemic human neonates (Tan and Parks, 1999).

\section{Outcome}

Vaala (2002) reported a survival rate of $70 \%$ to $80 \%$ in foals suffering from uncomplicated PAS. The prognosis is poorer in foals that develop concurrent sepsis, fail to show clinical improvement in five days, or experience serious seizures.

Future performance is not necessarily compromised in foals that survive without significant complications.

\section{Recognition of risk factors}

It is important to recognise risk factors and events and to anticipate the occurrence of perinatal asphyxia. Foals at risk include those born to mares that have previously delivered a PAS foal, had placental abnormalities, had difficult deliveries, or had a systemical illness or surgery during the current gestation. 


\section{Case report}

\section{History}

A Thoroughbred colt foal, 24-hour-old and weighing $50 \mathrm{~kg}$, was referred to the hospital with a history of acute onset seizure-like activity one hour previously. The foal had been born uneventfully to a pluriparous mare that had not had any problems with her previous foals nor had she shown any signs of illness during the recent 341-day pregnancy. The placenta was examined and found to be normal. The colt had exhibited normal activity after birth: he stood within 40 minutes, suckled the mare one hour after foaling, passed meconium without any problem. At 14 hours of age the concentration of immunoglobulin G was $>800 \mathrm{mg} / \mathrm{dl}$.

The foal was discovered at 24 hours of age lying in the stable exhibiting violent galloping-like activity and he could not be aroused. He was given $10 \mathrm{mg}$ diazepam intravenously $(0.2 \mathrm{mg} / \mathrm{kg}$ bwt $)$ almost immediately by the referring veterinarian.

\section{Clinical examination}

On admission, one hour after the onset of clinical signs, the foal was recumbent, exhibiting extensor rigidity of all four limbs, opisthotonous and nystagmus. Assessment of physical parameters revealed a temperature of $100.4^{\circ} \mathrm{C}$, heart rate of 104 beats per minute, respiratory rate of 40 breaths per minute with normal auscultation and slightly reduced gut motility. There was no evidence of trauma to the foal, either primary or secondary to the seizures.

\section{Clinical pathology}

Initial haematology was unremarkable (Table 2). There was mild azotaemia, elevated concentration of creatine kinase, and mild hypoglycaemia (most likely due to reduced enteral intake). Cerebrospinal fluid evaluation was within normal limits: white blood cell count $2.2 \times 10^{9} / \mathrm{L}$ (reference range: less than $5 \times 10^{9} / \mathrm{L}$; Furr and Bender, 1994) and total protein $1.6 \mathrm{~g} / \mathrm{L}$ (reference range: 0.4 to $1.7 \mathrm{~g} / \mathrm{L}$; Rossdale et al., 1982). Culture of blood taken on admission yielded a negative result.

\section{Treatment}

The immediate aim of treatment was to prevent and to control any further seizures. Once the initial clinical assessment was performed, $10 \mathrm{mg}$ of diazepam $(0.2 \mathrm{mg} / \mathrm{kg}$ bwt $)$ was administered intravenously (i.v.). This caused immediate muscle relaxation and reduced excitability; 20 minutes later a further $10 \mathrm{mg}$ diazepam was given i.v. Humidified oxygen was administered via nasal insufflation at a flow rate of $5 \mathrm{~L} /$ minute. An intravenous triple-lumen catheter (Mila International, Inc., Florence, Kentucky 42041, USA) was inserted into the right jugular vein: separate ports were used for administration of parenteral nutrition and for crystalloids; the third port was used

\section{TABLE 2: Clinical pathological findings in a Thoroughbred colt foal with perinatal asphyxia syndrome}

\begin{tabular}{|c|c|c|c|c|c|}
\hline & Admission & Day 2 & Day 3 & Day 4 & Reference range \\
\hline White blood cells $\times 10^{9} / \mathrm{L}$ & 9.3 & 15.6 & 11.0 & 9.7 & $3.7-12.1$ \\
\hline Haematocrit $\mathrm{L} / \mathrm{L}$ & 0.32 & 28.7 & 29.4 & 28.3 & $0.31-0.45$ \\
\hline Neutrophils $\times 10^{9} / \mathrm{L}$ & 6.6 & 9.5 & 6.2 & 6.3 & $1.7-10.1$ \\
\hline Lymphocytes $\times 10^{9} / \mathrm{L}$ & 2.5 & 5.3 & 4.7 & 3.0 & $0.5-2.9$ \\
\hline Fibrinogen $\mathrm{g} / \mathrm{L}$ & 2.0 & 2.5 & 3.0 & 3.0 & $1.7-3.2$ \\
\hline Total protein $\mathrm{g} / \mathrm{L}$ & 52 & 54 & 54 & 50 & $42-59$ \\
\hline Albumin $\mathrm{g} / \mathrm{L}$ & 28 & 26 & 28 & 26 & $26-34$ \\
\hline Globulin $\mathrm{g} / \mathrm{L}$ & 24 & 28 & 26 & 24 & $12-31$ \\
\hline Immunoglobulin G mg/dl & $>800$ & & & & $>800$ \\
\hline AST iu/L & 187 & 181 & 175 & 155 & $111-206$ \\
\hline Creatine kinase iu/L & 1258 & 856 & 354 & 288 & $165-761$ \\
\hline Blood urea nitrogen $\mathrm{mmol} / \mathrm{L}$ & 5.54 & 3.78 & 4.4 & 4.6 & $2.9-8.4$ \\
\hline Creatinine $\mu \mathrm{mol} / \mathrm{L}$ & 230 & 168 & 126 & 134 & $97-188$ \\
\hline GGT iu/L & 29 & 28 & 32 & 29 & $10-32$ \\
\hline Bilirubin (total) $\mu \mathrm{mol} / \mathrm{L}$ & 43 & 67 & 52 & 54 & $16-94$ \\
\hline Sodium mmol/L & 140 & 142 & 144 & 142 & $134-144$ \\
\hline Potassium mmol/L & 3.9 & 2.9 & 3.2 & 3.9 & $3.8-4.8$ \\
\hline Chloride mmol/L & 104 & 100 & 99 & 101 & $99-104$ \\
\hline Glucose $\mathrm{mmol} / \mathrm{L}$ & 3.1 & 7.7 & 11.5 & 9.4 & $4.8-9.9$ \\
\hline
\end{tabular}

AST: aspartate aminotransferase; GGT: gamma glutamyl transferase. 
for drug delivery. Crystalloid fluid therapy (polyionic fluids with supplemented glucose to make a $5 \%$ glucose solution) was administered at $10 \mathrm{ml} / \mathrm{kg}$ bwt $/ \mathrm{h}$ for the first hour; then, maintenance polyionic fluids (without glucose) were continued at $5 \mathrm{ml} / \mathrm{kg}$ bwt $/ \mathrm{h}$. Parenteral nutrition was initiated with a commercially available mixture (Clinomel, Baxter), which provided $1 \mathrm{kcal} / \mathrm{ml}$. Infusion was started at $30 \mathrm{kcal} / \mathrm{kg}$ bwt $/$ day and was gradually increased to $40 \mathrm{kcal} / \mathrm{kg}$ bwt/day over the next $12 \mathrm{~h}$. One hour after admission the glucose concentration had risen to $5.4 \mathrm{mmol} / \mathrm{L}$ and further measurements, taken every four hours, were within an acceptable range (4.8 to $9.9 \mathrm{mmol} / \mathrm{L})$.

A single treatment of $300 \mathrm{mg}$ allopurinol $(6 \mathrm{mg} / \mathrm{kg}$ bwt $)$ was administered via stomach tube.

Further treatments consisted of $50 \mathrm{~g}$ ( $\mathrm{lg} / \mathrm{kg}$ bwt) of dimethyl sulphoxide (DMSO) i.v. as a $5 \%$ solution q24h for five days (this was incorporated into the overall fluid requirements of the foal), $200 \mathrm{mg}$ vitamin $\mathrm{E}(4 \mathrm{mg} / \mathrm{kg}$ bwt $) / 2 \mathrm{mg}$ selenium $(0.04 \mathrm{mg} / \mathrm{kg}$ bwt) i.m. q24h for five days, $1 \mathrm{~g}$ magnesium sulphate $(20 \mathrm{mg} / \mathrm{kg}$ bwt) i.v. q24h for five days, $100 \mathrm{mg}$ ketoprofen $(2 \mathrm{mg} / \mathrm{kg}$ bwt $)$ i.v. q24h for five days. Empirical antibiotic therapy was initiated: $250 \mathrm{mg}$ ceftiofur ( $5 \mathrm{mg} / \mathrm{kg}$ bwt) i.v. q.i.d. and $330 \mathrm{mg}$ gentamicin $(6.6 \mathrm{mg} / \mathrm{kg}$ bwt $)$ i.v. q24h was introduced on day 2 , once the azotaemia had been controlled. Omeprazole $(1 \mathrm{mg} / \mathrm{kg}$ bwt) i.v. q24h was used as prophylactic therapy for gastric ulceration.

The foal was kept in a dark and very quiet environment to minimise the effects of external stimuli. He was maintained in sternal recumbency to aid ventilation and perfusion of the lungs, and was turned every two hours to prevent pressure sores. An indwelling urinary catheter was inserted and connected to a closed urine collection system.

There was no seizure over the following two hours but diazepam $(0.2 \mathrm{mg} / \mathrm{kg}$ bwt i.v. $)$ did not control seizure-like activity that occurred after that interval and $500 \mathrm{mg}$ phenobarbital $(10 \mathrm{mg} / \mathrm{kg}$ bwt $)$ was administered i.v. in $30 \mathrm{ml}$ of saline over 20 minutes. This regime was repeated every eight hours and any evidence of mild seizure breakthrough inbetween these treatments was treated with $5 \mathrm{mg}$ diazepam $(0.1 \mathrm{mg} / \mathrm{kg}$ bwt $)$ i.v.

During the 12 hours following presentation, there was no evidence of respiratory depression and abdominal auscultation revealed normal borborygmi. An indwelling 10Fr (radioopaque) nasogastric tube (Mila International, Inc., Florence, Kentucky 42041 , USA) was inserted and enteral feeding was initiated. Small volumes of mare's milk $(50 \mathrm{ml} / \mathrm{h})$ were fed and this was tolerated very well, there was no reflux at any time, and this volume was increased to $100 \mathrm{ml} / \mathrm{h}$ over the next $24 \mathrm{~h}$.

Urine production was monitored closely, and hourly rates and specific gravity were recorded. In the first $24 \mathrm{~h}$, urine was produced at the rate of $140 \mathrm{ml} / \mathrm{kg}$ bwt/day and specific gravity was within normal limits (1.001 to 1.009). Total infusates (enteral and i.v.) in the first $24 \mathrm{~h}$ were roughly $8.5 \mathrm{~L}$; thus, the ouput of urine during that interval was approximately $80 \%$ of the fluid delivered. During the following three days urine production rates varied from $72 \%$ to $86 \%$ of fluid delivered.

On day 2 of hospitalisation, the foal had intermittent mild seizure activity despite the continued phenobarbital therapy $(10 \mathrm{mg} / \mathrm{kg}$ bwt i.v. t.i.d.). Enteral and parentral nutrition were continued. Maintenace intravenous fluids were continued at $3 \mathrm{ml} / \mathrm{kg}$ bwt $/ \mathrm{h}$. Potassium chloride $(20 \mathrm{mmol} / \mathrm{L})$ was added to i.v. fluids, to correct the hypokalaemia (Table 2). A leukocytosis was present with neutrophilia and lymphocytosis; creatinine had returned to normal values and creatine kinase was reducing (Table 2). One litre of a commercial hyperimmunised plasma was administered over three hours. Intravenous omeprazole therapy was discontinued and replaced by oral omeprazole $50 \mathrm{mg}(\mathrm{lmg} / \mathrm{kg}$ bwt $)$ q $24 \mathrm{~h}$. Nasal oxygen therapy was continued at $5 \mathrm{~L} /$ minute. Clinical examination was unremarkable, respiratory rate remained stable, and abdominal auscultation revealed consistent normal gut motility. Milk-based normal faeces were being passed. There was no gastric reflux.

On the morning of day 3 , the phenobarbital dose was reduced to $8 \mathrm{mg} / \mathrm{kg}$ bwt i.v. t.i.d. Enteral $(100 \mathrm{ml} / \mathrm{h})$ and parenteral (40 kcal/kg bwt/day) nutrition was continued. Maintenance intravenous fluid therapy $(3 \mathrm{ml} / \mathrm{kg}$ bwt $/ \mathrm{h})$ was supplemented with potassium chloride $(20 \mathrm{mmol} / \mathrm{L})$, as a mild hypokalaemia persisted. White blood cell count and creatine kinase concentration had returned to normal. There was a mild hyperglycemia for a short period during day 3 (Table 2 ). Oxygen therapy was continued at $5 \mathrm{~L} /$ minute. During the following eight hours there was one episode of extensor rigidity and opisthotonus, which responded to $5 \mathrm{mg}$ diazepam $(0.1 \mathrm{mg} / \mathrm{kg}$ bwt $)$ i.v. Auscultation of the lungs at this time revealed increasingly harsh inspiratory and expiratory noises. Ultrasonography showed bilateral mild pleural thickenings with small areas of consolidation $(<0.3 \mathrm{~cm})$ on the surface of the lungs. Twice daily nebulisation with $80 \mathrm{mg}$ gentamicin (1.6mg/kg bwt) was initiated.

On the morning of day 4 , phenobarbital treatment was reduced to $5 \mathrm{mg} / \mathrm{kg}$ bwt i.v. During the following eight hours the foal became more alert, without evidence of hyperexcitation. Intravenous phenobarbital was discontinued and $100 \mathrm{mg}$ oral phenobarbital $(2 \mathrm{mg} / \mathrm{kg}$ bwt $\mathrm{ql} 2 \mathrm{~h}$ ) was administered p.o. on the evening of day 4 . Enteral nutrition was increased to $150 \mathrm{ml}$ mare's milk every hour, parenteral nutrition was reduced to $30 \mathrm{kcal} / \mathrm{kg}$ bwt $/$ day. Maintenance fluid therapy, supplemented with $20 \mathrm{mmol}$ potassium chloride per litre, was continued at $3 \mathrm{ml} / \mathrm{kg}$ bwt $/ \mathrm{h}$. Clinical pathology on day 4 was unremarkable (Table 2).

On the morning of day 5 , the foal was assisted to stand for a few minutes each hour. The urinary collection system was removed. The foal exhibited an increasing interest in the mare; however, he did not have a suck reflex. Feeding by indwelling nasogastric tube continued and was increased to $200 \mathrm{ml} / \mathrm{h}$. Parenteral nutrition was decreased to $15 \mathrm{kcal} / \mathrm{kg}$ bwt/day. 
Maintenance fluid therapy was decreased to $2 \mathrm{ml} / \mathrm{kg}$ bwt $/ \mathrm{h}$. When he stood, the foal urinated normally, with exteriorised penis; there was mild urinary tenesmus, most likely due to urethritis, a sequel to catheterisation. Normal to soft milk-based faeces were being passed. Clinical pathology did not show any abnormalities on day 5 . Phenobarbital therapy was discontinued on the evening of day 5 .

On day 6 , the foal stood unassisted and the suck reflex started to return; however, he had no interest in sucking the mare. Enteral nutrition was increased to $250 \mathrm{ml} / \mathrm{h}$ via the indwelling stomach tube. Parenteral nutrition was withdrawn during day 6 . Fluid therapy was continued at $3 \mathrm{ml} / \mathrm{kg}$ bwt $/ \mathrm{h}$. DMSO, vitamin $\mathrm{E}$, magnesium and ketoprofen therapies were discontinued at this stage. Clinical pathology was unremarkable. Fluid therapy was reduced to $2 \mathrm{ml} / \mathrm{kg}$ bwt/day.

On day 7 , the foal was assisted to nurse from the mare and nasogastric feeding and fluid therapy were reduced as the amount of suckling increased during the following $12 \mathrm{~h}$. The indwelling stomach tube was removed on the morning of day 8 . Auscultation and ultrasonography of the lungs showed a satisfactory improvement in the condition of the lung and nebulisation was discontinued on the evening of day 8 , as were fluid and oxygen therapies.

The foal continued to make excellent clinical progress and he was discharged from the hospital on day 12. Antibiotic therapy (5mg ceftiofur $/ \mathrm{kg}$ bwt i.m. q12h) and omeprazole ( $\mathrm{lmg} / \mathrm{kg}$ bwt p.o. q24h) were continued for a further seven days. Over the following year, the foal had no health problems.

\section{Discussion}

This foal would be assigned to category one as described by Hess-Dudan and Rossdale (1996a). He had a normal birth with normal postnatal activity, but the clinical symptoms of PAS started at $24 \mathrm{~h}$ of age.

After initial anticonvulsive therapy and stabilisation, the next step was to investigate the cause of the seizures. The differential diagnoses mentioned by Vaala (2002) had to be considered. There was no evidence of external trauma or of congenital anomalies. CSF analysis was within normal limits, as were serum electrolyte concentrations at the time of admission. On the bases of these observations and the clinical signs, a diagnosis of PAS was made.

There was a mild increase in plasma creatinine concentration, which was most likely a reflection of prepartum placental insufficiency; this was within normal limits by day 2 . The elevated creatine kinase may correlate with a hypoxic-ischaemic insult to the foetus while in utero or at birth (Madigan, 1997); however, it may also be an indicator of muscle trauma either at birth or after.

Septicaemia is a frequent sequel to perinatal asphyxia; therefore, although the leukogram was normal and the blood culture was negative when the foal was admitted, antimicrobials were added to the treatment regime.
The foal showed no evidence of gastrointestinal dysfunction (reflux, ileus); enteral feeding via indwelling stomach tube was tolerated, in progressively increasing amounts. Partial parenteral nutrition was introduced in the first 24 hours and withdrawn gradually once enteral intake increased. Complications from parenteral nutrition that we experienced were the hypokalaemia on day 2, and mild transient hyperglycaemia on day 3 . Administration of polyionic fluid supplemented with $20 \mathrm{mmol}$ potassium chloride/L helped to restore the serum potassium concentration to normal.

Close monitoring of all organ systems is important and allows early aggressive intervention, if necessary. Monitoring urine production and specific gravity gave an indication of the cardiovascular status of the foal. As there were no ongoing losses due to diarrhoea or gastric reflux, maintenance requirements would be 5 to $6 \mathrm{ml} / \mathrm{kg}$ bwt $/ \mathrm{h}$ of a balanced polyionic fluid.

This foal was maintained on intranasal humidified oxygen from admission until day 8. Blood gases were not measured; that would have provided a useful indication of the oxygen status of the foal while recumbent and would have given us information regarding any secondary hypoxaemia as a result of the lung pathology noted on day 3 .

This case shows the need for multisystemic therapy in foals suffering from PAS. Cardiovascular, electrolyte, respiratory and nutritional supports were instigated in addition to anticonvulsive therapy and therapies aimed specifically at the ongoing pathophysiology.

\section{References}

Brewer, B.D., Clement, S.F., Lotz, W.S. and Gronwall, R. (1990). A comparison of inulin, paraminohippuric acid, and endogenous creatinine clearances as a measure of renal function in neonatal foals. Journal of Veterinary Internal Medicine 4: 301-305.

Buchanan, B., Andrews, F., Sommardahl, C. and Rohrbach, B. (2003). Effect of a 24-hour infusion of an isotonic replacement fluid on the renal excretion of sodium in healthy 4-day-old foals. Abstract in Journal of Veterinary Emergency and Critical Care 13: 174-175.

Corley, K.T.T. (2002a). Monitoring and treating haemodynamic disturbances in critically ill neonatal foals. Part 1: Haemodynamic monitoring. Equine Veterinary Education 14: 270-279.

Corley, K.T.T. (2002b). Monitoring and treating haemodynamic disturbances in critically ill neonatal foals. Part 2: Assessment and treatment. Equine Veterinary Education 14: 328-336.

Corley, K.T.T. (2003). Perinatal asphyxia syndrome. Proceedings of the Foal Care Course, Newmarket. pp17-22.

Furr, M.O. (1996). Perinatal asphyxia in foals. Compendium on Continuing Education for the Practicing Veterinarian 18: 1342 1351.

Furr, M.O. and Bender, H. (1994). Cerebrospinal fluid variables in clinically normal foals from birth to 42 days of age. American Journal of Veterinary Research 55: 781-784.

Hess-Dudan, F. and Rossdale, P.D. (1996a). Neonatal maladjustment 
syndrome and other neurological signs in the newborn foal: Part 1 . Equine Veterinary Education 8: 24-32.

Hess-Dudan, F. and Rossdale, P.D. (1996b). Neonatal maladjustment syndrome and other neurological signs in the newborn foal: Part 2. Equine Veterinary Education 8: 79-83.

Madigan, J.E. (1997). Manual of Equine Neonatal Medicine. Third edition. California: Live Oak Publishing.

Rossdale, P.D., Cash, R.S.G., Leadon, D.P. and Jeffcott, L.B. (1982). Biochemical constituents of cerebrospinal fluid in premature and full term foals. Equine Veterinary Journal 14: 134-138.

Tan, S. and Parks, D.A. (1999). Preserving brain function during neonatal asphyxia. Clinical Perinatology 26: 733-747.

Vaala, W.E. (1994). Peripartum asphyxia. Veterinary Clinics of North America: Equine Practice 10: 187-218.

Vaala, W.E. (2002). Perinatal asphyxia syndrome in foals. In: Current Therapy in Equine Medicine 5. Edited by N.E. Robinson. Philadelphia: Saunders. pp644-649.

Volpe, J. (1995). Hypoxic-ischemic encephalopathy: Biochemical and physiological aspects. In: Neurology of the Newborn. Edited by J. Volpe. Philadelphia: Saunders. pp211-259.

Westbrook, G.L. (1993). Glutamate receptors and excitotoxicity. In: Molecular and Cellular Approaches to Treatment of Neurological Disease. Edited by S.G Waxman. New York: Raven Press.

Wilkins, P.A. (2001). Magnesium infusion in hypoxic ischaemic encephalopathy. Proceedings of the Annual Veterinary Medical Forum, American. College of Veterinary Internal Medicine, pp 242244. 